Francesco Riccobono. Francesco Riccobono es Catedrático de Filosofía del Derecho de la Università di Napoli Federico II. También es Vicepresidente de la SIFD, Società Italiana di Filosofia del Diritto. Se ha ocupado del pensamiento de Hans Kelsen y, más recientemente, de las temáticas de la interpretación jurídica, de los derechos humanos y del Estado constitucional de derecho. Junto con Andrea Bixio y Pietro Rescigno, dirige la colección "Bibliotheca. Biblioteca di studi giuridici politici e sociali", y con Adriano Ballarini, Massimo La Torre y Eugenio Ripepe, la colección "La nottola di Minerva", editadas por Giappichelli. Entre sus obras más recientes, se encuentran: "Diritto e 'vita sociale' in Emilio Betti", en Sociología, 1, 2012; "Kelsen e la religione”, en Rivista di filosofia del diritto, 2013; “Giustizia \& Giustizia”, en Parolechiave, 53, 2015.

Contacto: francesco.riccobono@unina.it 


\title{
METAMORFOSIS DEL CONCEPTO DE LEGALIDAD
}

\author{
Francesco Riccobono
}

Università degli Studi di Napoli Federico II

\section{METAMORPHOSIS OF THE CONCEPT OF LEGALITY}

DOI: 1017450/160103

Fecha de recepción 16 de febrero de 2015; fecha de aceptación 28 de marzo de 2015. Este artículo es la elaboración escrita de la comunicación Diritto e potere: metamorfosi del principio di legalità, que el autor presentó el 23 de septiembre de 2015 en la conferencia "Hard e Soft Power: coesistenza o conflitto di paradigmi?" en la Università degli Studi di Salerno, y se ha realizado en el marco del proyecto de investigación desarrollado en el Dipartimento di Scienze Sociali, Università di Napoli Federico II.

\section{Resumen}

Las palabras que revelan conceptos esenciales y situaciones fundamentales de la teoría y de la práctica jurídica y política no siempre tienen el mismo significado, sino que adquieren significados diferentes con relación a las diversas configuraciones históricas y geográficas de la sociedad civil y de la sociedad política. Lo mismo ocurre con el principio de legalidad y con el concepto de legalidad con este relacionado. En este artículo, queremos esbozar un cuadro del cambio del concepto de legalidad con referencia a la evolución de la forma de Estado -de Estado de derecho a Estado social- y al Estado constitucional. La última metamorfosis de la legalidad parece destacar la pérdida o, por 
lo menos, una crisis profunda de elementos fundamentales -antes que todo, el elemento de la certeza del derecho- que habían caracterizado la estructura y los ideales del concepto tradicional de legalidad.

\section{Palabras clave}

Legalidad, principio de legalidad, Estado de derecho, Estado social, Estado constitucional

\section{Abstract}

The words expressing essential concepts and fundamental ideas about legal and political theory and practice do not always recur with the same meaning, but they assume a different meaning depending on the different historical and geographical configurations of the civil and political society. The same thing is for the rule of law and for the relative concept of legality. Here, we want to give a hint of how the concept of legality has changed with reference to the evolution of the form of the State, from the legal State to the social State and, finally, to the constitutional State. The last metamorphosis of legality seems to show the loss, or at least, a deep crisis of fundamental elements, first of all the certainty of law, which had marked the structure and the ideals of the traditional concept of legality.

\section{Key words}

Legality, rule of law, legal state, social state, constitutional state

Con el paso del tiempo, las palabras y los conceptos que caracterizan habitualmente la teoría y la doctrina del derecho han sido afectados por cambios de significado tan evidentes como para modificar con profundidad lo que, a primera vista, puede parecer idéntico. La reflexión acerca de las metamorfosis factuales y conceptuales del derecho no es algo nuevo. ${ }^{1}$ Creemos que esa reflexión puede ser útil para explicar un término (legalidad) que se repite en la teoría y en la práctica del derecho. ${ }^{2}$

1. A este propósito no podemos sino recordar el análisis de Alfonso Catania sobre la evolución de los conceptos de norma, decisión y ordenamiento. A. Catania, Metamorfosi del diritto. Decisione e norma nell'età globale, Laterza, Roma-Bari, 2008. 2. Queremos señalar algunas obras sobre el argumento que destacan el gran interés actual hacia la dimensión "global" de la legalidad: G. Acocella (ed.), Materiali per una cultura della legalità, Giappichelli, Torino, 2014 y Id. La legalità ambigua, 
Legalidad no es un concepto simple ni unívoco. En la experiencia jurídica continental más tardía, la claridad del ideal revolucionario e igualitario de la légalité desaparece frente a la complejidad de una tríada de términos no totalmente intercambiables: legalität, gesetzlichkeit, gesetzmäßigkeit. En la clásica oposición a legitimität, legalität marcaba el término de la época de la legitimidad. El nuevo poder legítimo es -como diría Weber- el poder legal, es decir, el poder estructurado racionalmente en la forma de leyes generales y abstractas. La forma de la ley es la juspositivística de la gesetzlichkeit, de la ley "puesta" en la que la acción de los organismos jurídicos - del Estado al ciudadano- debe adaptarse a la gesetzmäßigkeit, es decir, "conforme a la ley”.

Diríamos que se trata de un itinerario mental bastante lineal si no fuera porque, entre finales del siglo XIX y principios del siglo XX, las potencialidades lexicales de la gesetzlichkeit prevalecen sobre las de la legalität. Ocurre algo similar a la diferencia entre justiz y gerechtigkeit ${ }^{4}$, que significan obviamente justicia. Sin embargo, la primera (justiz) atañe al aspecto institucional de la justicia, la jurisdicción; la segunda (gerechtigkeit) indica el valor de la justicia, el valor que fundamenta toda convivencia civil. La palabra de origen neolatino adquiere un significado "débil": en la experiencia jurídica, la existencia de la justiz presupone que los hombres crean en una gerechtigkeit, en la que descansa la raíz del derecho, del recht que, además, está insertado en la gerechtigkeit. En nuestro caso, legalität describe las formas y las técnicas de un ordenamiento jurídico que se basa en el dominio de leyes generales y abstractas, dictadas por hombres y para hombres.

En cambio, gesetzlichkeit no solo atañe al ámbito de la legislación positiva o de cualquier otra modalidad "positiva” de producción del derecho, sino también está convencida de que la sociedad solo puede ser animada por un principio jurídico. Esto se destaca con claridad en las disputas metodológicas a caballo entre los dos siglos: el debate sobre la gesetzlichkeit a menudo se cuela en el debate sobre la eigengesetzlichkeit que caracteriza y estructura universos - la sociedad, la historia, el mismo derechoalcanzables por el conocimiento humano gracias a la individuación de su especificidad. Eigengesetzlichkeit se puede traducir como "autonomía” en sentido fuerte, claro

\footnotetext{
Giappichelli, Torino, 2013, en donde se halla también el interesante y profundo ensayo del mismo Acocella, "Paradigmi della legalità", pp. 1-93. Por lo que al principio de legalidad en los ámbitos positivos, interno y europeo, del derecho constitucional, del derecho administrativo, del derecho tributario y en el ámbito internacionalista del derecho penal y del desarrollo de una justicia global se refiere, véanse los ensayos presentes en F. Viola (ed.), Lo Stato costituzionale di diritto e le insidie del pluralismo, il Mulino, Bologna, 2012. Sobre la idea de una legalidad global, cfr. G. Palombella, Ė possibile una legalità globale? Il Rule of law e la governance del mondo, il Mulino, Bologna, 2012.

3. Una verdadera duplicación: Gesetz es al mismo tiempo lex y positum (del verbo setzen = poner).

4. Sobre esta distinción, nos permitimos remitir a F. Riccobono, “Giustizia \& Giustizia”, en Parolechiave, 53, 2015, pp. 1-16.
} 
está, o bien, más adecuadamente o quizás de forma más sofisticada, como “idionomía”, indicando el conjunto de leyes que describen y posibilitan la existencia específica y el desarrollo de mundos y ámbitos de vida. A este propósito, tal vez alguien se acuerde del viejo término de ciencias “idiográficas”. Pues bien, en la gesetzlichkeit de la que habla la ciencia del derecho hay muchas señales de esta forma que, a su vez, configura universos y ámbitos vitales. En este caso, gesetzlichkeit es mucho más que la centralidad del poder legislativo y la construcción de un ordenamiento jurídico creado para ello; es el reconocimiento de las capacidades que el derecho tiene de estructurar el mundo social y todo ámbito de vida. Podríamos decir, pues, que gesetzlichkeit denota el elemento constitutivo de un mundo y que, en el caso de la sociedad de los hombres, este elemento constitutivo es el derecho.

Todavía no nos hemos referido a la relación entre Estado y legalidad, lo cual puede parecer extraño si consideramos que el concepto de legalidad limita mucho el poder del Estado y de sus órganos, por confiar en el gobierno de las leyes y no en el de los hombres. Nos parecerá menos extraño cuando expliquemos el itinerario histórico y conceptual de la legalidad, tanto como legalität y como gesetzlichkeit.

En la legalität (légalité) está claro que el eje del proceso, el punto de vista principal de la formulación y formación del concepto no remite a una subjetividad estatal dominante. En este caso, la legalidad describe a la perfección la naturaleza, el funcionamiento y los objetivos del Estado de derecho, es decir, de aquella forma de Estado obligada a aceptar las presiones y las necesidades de la "sociedad burguesa" contra el autoritarismo del Estado obsoluto a principios del siglo XIX. En un famoso ensayo de los años sesenta, Ernst-Rudolf Huber explica con claridad que así como el concepto de "sociedad burguesa" era un "concepto de polémica social", el concepto de "Estado de derecho burgués" era un "concepto de polémica política".

Así, con el concepto de legalidad se fija el éxito político y social de la sociedad burguesa. Tal y como subraya Huber, la legalidad del Estado de derecho parecía ser -y en aquel entonces incluso era- la mejor garantía de aquel ámbito absolutamente intocable de la vida, de la libertad y de la propiedad personal. ${ }^{5}$ Está claro que hablamos de una "legalidad formal" que, a su vez, es un concepto provocador. Quiere decir que la supremacía del legislativo - basada en los tres principios de la fuerza de ley, de la supremacía de la ley y de la reserva de ley- nunca podrá dar lugar a una supremacía personal del legislador capaz de decidirlo todo. Las competencias del legislativo atañen a la seguridad,

5. E. R. Huber, Nationalstaat und Verfassungsstaat. Studien zur Geschichte der deutschen Staatsidee (1962), Kohlhammer, Stuttgart, 1965, pp. 249-272. 
a la libertad y a la propiedad -eso se destaca en la clásica distinción entre ley en sentido formal y ley en sentido material-, y sus decisiones se limitan a ofrecer protección a esos bienes, aceptando contenidos que se han afianzado en la praxis de la sociedad burguesa y que ya han sido aceptados por los bourgeois. De hecho, la época del Estado legislativo es la época del Estado “guardián nocturno”. La sociedad burguesa quiere estar tranquila; la legalidad la ayuda en eso, delimitando el ámbito de acción del derecho del Estado.

En realidad, no solo el derecho del Estado está limitado. En sus principios, toda la sociedad burguesa sobrepasa los recorridos jurídicos y se mueve en el "espacio sin derecho", del que habla fantásticamente la doctrina jurídica dieciochesca. El alma, el aliento de vida de la sociedad burguesa no es un alma jurídica; el derecho será el remedio cuando "la insociable sociabilidad" de la sociedad burguesa supere un nivel fisiológico de conflictividad.

Así que, el principio de legalidad -siendo conforme a la ley- nace con dos objetivos: rechazar el elemento personal y personalístico del poder, y también liberar a la sociedad de las riendas del derecho, del derecho en general. El primer objetivo es de difícil discusión y Schmitt lo fija con claridad cuando dice que el significado más importante del “'Prinzip der Gesetzmäßigkeit' alles staatlichen Lebens liegt darin, daß schließlich überhaupt nicht mehr geherrscht oder befohlen wird, weil nur unpersönlich geltende Normen geltend gemacht werden"6. El segundo lo podemos entender, sobre todo, con referencia a la profundidad de acción y a la aceptación compartida del principio del laisser faire en la formación de la sociedad burguesa como sistema de la economía política, y también con referencia al déficit de eficacia de los sistemas jurídicos privatísticos y publicísticos, pues es el mismo motivo que llevará más tarde Georg Jellinek a reconocer la exigüidad material del concepto de soberanía del Estado. ${ }^{7}$

La espera optimista de Huber -a la que se dedicó meticulosamente la ideología del Estado de derecho- de que se constituya un orden social en la base de la ley de la armonía prefijada por las fuerzas, a través de la total libertad del individuo, sin la intervención social del Estado, ${ }^{8}$ pronto fue vana. Al derecho le fueron otorgadas otras tareas, como tutelar un mundo ya bien ordenado y crear él mismo el orden del mundo social. La gesetzlichkeit no es solo el atributo del Estado y el principio de su funcionamiento, sino también indica, en sentido fuerte, el origen no natural sino espontáneo de todo orden social; pues su esbozo positivo, artificial, a manos de sujetos -el legislador, pero

6. C. Schmitt, Legalität und Legitimatat (1932), Duncker \& humblot, Berlín, 1968, p. 8.

7. Cfr. G. Jellinek, Das Recht des modernen Staates. I Allgemeine Staatslehre, Häring, Berlín, 1905, pp. 421-490.

8. Cfr. E. R. Huber, Nationalstaat und Verfassungsstaat, p. 153. 
también y sobre todo los administradores, los funcionarios, los juristas- que poseen y ponen en práctica la técnica jurídica. Gesetzlichkeit revela rasgos técnico-jurídicos que la legalität no posee, comprometida como está en su lucha político-ideal contra la legitimität. De ahí que el orden social sea el fruto de la acción jurídica de dominantes y dominados, por ende, de los afiliados en general. Podríamos decir que el derecho forma el orden social, la sociedad bien ordenada, la sociedad tout court. Así que gesetzlichkeit parece ser la mejor palabra para expresar el sistema de legalidad de la nueva forma de Estado, el Estado social. El Estado de derecho se da cuenta de sus faltas con respecto a la justicia material, a la materielle gerechtigkeit, que ahora se considera necesaria para tutelar la personalidad individual.

Del Estado de derecho se pasa al Estado social para darle al individuo condiciones materiales de existencia “más justas” y "más dignas”, e influir directamente en los equilibrios sociales y económicos. El equilibrio entre continuidad y ruptura en el tránsito del Estado de derecho al Estado social -el primer Estado se contiene y el segundo interviene- se desprende muy bien, histórica y teóricamente, del concepto de "Estado de derecho", que no deriva de un sincretismo mecánico, sino de una sincera y recíproca interacción de las dos formas de Estado. Para Huber, el verdadero Estado social presupone el Estado de derecho y viceversa. ${ }^{9}$ Desde esta perspectiva, está claro que si para el Estado de derecho la sociedad burguesa lucha contra el Estado, el Estado social no implica una revancha del Estado respecto de la sociedad, que ahora es una sociedad burguesa avanzada y muy industrializada. El nuevo Estado social debe interpretarse a través del concepto de leistung, de "prestación”. La intervención del Estado es pedida y exigida por individuos - no robinsoniamente aislados, sino concretamente identificados en su pertenencia de clase, en su existencia de trabajadores asalariados- que advierten el gran peligro que se cierne sobre el libre desarrollo de su personalidad y de su vida. Una vez más, el Estado no es el objetivo sino el medio de la sociedad. Cuando después de poco tiempo el Estado se proclame "objetivo" de la sociedad y de los individuos, él mismo se convertirá en "Estado total”. Por ahora, la sociedad sigue siendo el sujeto político principal; como mucho, al Estado se le puede definir un "servidor incómodo", un coprotagonista de la escena. Sin embargo, las dimensiones de esta presencia siguen siendo limitadas, tal y como se puede destacar si lo parangonamos con el "Estado total".

De ahí que, detrás del concepto de legalidad, se halle la dinámica entre sociedad y Estado en una relación orientada a la preeminencia de la sociedad. ¿Pasa lo mismo

$\overline{\text { 9. Cfr. Ibid., p. } 159 .}$ 
con el concepto de legalidad que emerge de la experiencia del Estado constitucional de derecho? No es fácil contestar a esta pregunta, sobre todo si pensamos en que se cruzan históricamente dos fenómenos diferentes, es decir, el Estado constitucional de derecho -a una determinada altura de su evolución- choca con la globalización. Ambos están caracterizados por una estrategia de superación de la realidad y de la idea de soberanía estatal, pero puede ser que esta convergencia implique finalidades diferentes. Si bien en este artículo solo nos ocupamos de la legalidad del Estado constitucional de derecho, podemos deducir que algunos puntos se pueden aplicar también a la legalidad en el mundo globalizado. Hay algunos rasgos comunes que atañen a la parcial superposición temporal y a la pertenencia a la misma dimensión jurídica. Sin embargo, no es el mismo proceso. Otros aspectos de la globalización jurídica -como los derivados de concepciones neoliberalistas que han llevado a un aumento salvaje del ámbito financiero y a un relativo empobrecimiento generalizado de las poblaciones productivas ${ }^{10}$ - se contraponen claramente con postulados fundamentales del Estado constitucional de derecho.

"Legalidad" en el Estado constitucional de derecho es un concepto fundamental relacionado con la misma imposibilidad de concebir un derecho que no tenga determinados requisitos de justicia, aquellos definidos en el sistema de los derechos humanos, aceptados y declarados en las constituciones democráticas posbélicas y en diferentes tratados y documentos normativos internacionales. Con la distinción entre principio de mera o lata o formal o legislativa legalidad y principio de estrecha o fuerte o sustancial o constitucional legalidad -distinción explicada muy bien por Luigi Ferrajoli1 ${ }^{11}$, ya es generalmente aceptada y fijada, de forma definitiva, la insostenibilidad de un criterio de legalidad que se contente con el "quién" o con el "cómo" sin analizar el "qué" de las decisiones jurídicas. ${ }^{12}$ Así que muchos consideran que la legalidad no se agota de conformidad con el ordenamiento jurídico (la tradicional gesetzmäßigkeit), sino que penetra y se completa -en palabras de Robert Alexy- en la "integridad de los contenidos", que pone de manifiesto una idea de justicia o, por lo menos -recordando la fórmula de Radbruch-, de rechazo de la injusticia. ${ }^{13}$ Esta opinión se puede manifestar por medio de un

\footnotetext{
10. A este propósito, véase el lúcido análisis de Alessandro Ferrara sobre la "financiarización de la economía capitalista" como factor de crisis de la democracia actual. Cfr. A. Ferrara, "La democrazia fra crisi e trasformazione”, en L. Bazzicalupo (ed.), Crisi della democrazia, Mimesis, Milano-Udine, 2014, pp. 273-289.

11. Cfr. L. Ferrajoli, La democrazia attraverso i diritti, Laterza, Roma-Bari, 2013, pp. 20-22.

12. Podemos decir que el "qué" del principio de legalidad está muy relacionado con el carácter sustantivo de los derechos fundamentales. Por eso, Francisco Javier Ansuátegui Roig habla de un "principio de legalidad selectiva” -que se basa, pues, en el carácter sustantivo de los derechos fundamentales- que marca el ocaso de una concepción formal de la legalidad. Véase F. J. Ansuátegui Roig, Razón y voluntad en el Estado de Derecho. Un enfoque filosófico-jurídico, Dykinson, Madrid, 2013, pp. 191-214.

13. Una versión breve y eficaz del pensamiento de Alexy se encuentra en R. Alexy, "El No Positivismo Incluyente", en Doxa
} 
abigarrado abanico de posiciones, entre ellas muy conflictivas, sobre todo con respecto a la naturaleza y al fundamento de los parámetros de corrección. Sin embargo, sobre todas recae la sombra del "Estado total"; se trata de posiciones que resienten el angustioso peso de la historia y coinciden en decir "nunca más". Su comunión teórica y doctrinal es derrotada por la urgencia de la historia. Los cambios funcionales de esta "legalidad enriquecida" - antes imaginada contra el poder total de pocos, luego adaptada al poder, que se supone totalizante, de la mayoría- no logran desenfocar sus rasgos originarios.

No creemos que esta legalidad "fuerte" pueda acompañar de forma exhaustiva la acción de uno de los dos sujetos tradicionales en juego. No podemos hablar simplemente de una sociedad contra el Estado o de un Estado en función de los pedidos sociales o de un Estado que domina a la sociedad o de un Estado que guía a la sociedad. La legalidad "fuerte" del Estado constitucional de derecho indica más bien una tendencia a la disolución de dos sujetos excelentes de la teoría política. La sociedad está caracterizada por un proceso de disgregación que impide una representación no contradictoria de las expectativas políticas. El Estado pierde la centralidad de la orientación política y acaba identificándose con equilibrios y balances entre agregados contingentes de intereses y valores. Entre sociedad y Estado se inserta el derecho como pedido relativamente independiente, que reglamenta situaciones de vida asociada desconectadas de los significados clásicos de "sociedad". En el escenario se impone una constelación de actores -y no sujetos- cuya identidad está asegurada por una estructura organizativa jurídica -pensemos en la clarividencia teórica del institucionalismo romaniano- y por la adhesión a una muy vaga idea de integridad.

Definimos la "legalidad" como término que identifica el derecho como "principio regulador de la vida social", ${ }^{14}$ pero que se diferencia bastante de los mundos vitales reglamentados por la gesetzlichkeit. En ese caso, la legalidad era un principio que daba un orden unitario al mundo social, un orden, pues, que se reflejaba en el postulado de la unidad del objeto de la ciencia del derecho. En cambio, ahora la legalidad expresa la extrema fragmentación de un universo jurídico compuesto por mónadas autosuficientes que se comunican entre ellas en la base de formas indeterminadas y casuales. De este universo poblado de fragmentos de derecho -los diferentes derechos que caracterizan a la multitud infinita de instituciones y organizaciones nacionales, supernacionales,

\footnotetext{
36, 2013, pp. 15-23; "The Nature of Legal Philosophy", en Associations, 7, 2003, pp. 63-75; "My Philosophy of Law: The Institutionalisation of Reason", en L. J. Wintgens (ed.), The Law in Philosophical Perspectives. My Philosophy of Law, Kluwer, Dordrecht-Boston-London, 1999, pp. 23-45.

14. B. Pastore, Decisioni e controlli tra potere e ragione. Materiali per un corso di filosofia del diritto, Giappichelli, Torino, 2013, p. 90.
} 
internacionales-, solo tenemos conocimientos sectoriales que no atañen a la ciencia sino a la técnica jurídica. Esto nos lo confirman dos rasgos del derecho actual por los que se ha interesado mucho la reciente filosofía del derecho. El primero es la "crisis" del sistema de las fuentes, que ya no es un sistema vertical y jerarquizado de normas y de poderes productivos de normas, sino una red horizontal de materiales normativos a disposición de intérpretes y órganos de la aplicación, legitimados para negociar cada vez su valor. ${ }^{15}$ El segundo es la pérdida de certeza del derecho, una expresión que, en el pasado, hacía dudar acerca de las “ficciones” de la ideología jurídica de una elite ilustrada de juristas-filósofos a propósito de la previsibilidad de todo procedimiento jurídico ${ }^{16}$ y que, hoy día, representa la trágica conciencia general de que el derecho actual es un arcanum, que solo un jurista muy especializado y profesionalizado puede entender, una degeneración, pues, a la que se intenta poner remedio remitiendo - un resultado difícil de lograr-a los "fundamentos axiológicos positivos del ordenamiento."17

Con la pérdida de tres elementos fundamentales del antiguo principio de legalidad -accesibilidad de las fuentes, posibilidad de conocer los textos normativos y certeza del derecho- constatamos la actual metamorfosis del concepto de legalidad. Es difícil extraer lo que queda del valor político de la légalité o de la ambición jurídico-social de la gesetzlichkeit. Tal vez tendríamos que crear otra palabra.

Traducción del italiano de M. Colucciello

15. Cfr. G. Pino, Interpretazione e "crisi" delle fonti, Mucchi, Modena, 2014. Se ha interesado por los aspectos de continuidad y novedad del principio de legalidad en la práctica interpretativa del derecho también B. Pastore, Interpreti e fonti nell'esperienza giuridica contemporanea, Cedam, Padova, 2014, pp. 35-41.

16. Hablamos de la denuncia kelseniana de la "ilusión" del dogma de la certidumbre del derecho. Cfr. H. Kelsen, Reine Rechtslehre. Einleitung in die rechtswissenschaftliche Problematik (1934), Mohr Siebeck, Tübingen, 2008, p. 109.

17. V. Omaggio, Saggi sullo Stato costituzionale, Giappichelli, Torino, 2015, p. 66. 